\title{
Yusuf Atılgan'ın "Çıkılmayan" Adlı Öyküsünde Gölge Arketipi ve Kitle Psikolojisi
}

\author{
ABDULLAH TURUT* \\ Öz
}

Edebî eserlerde arketipler farklı şekillerde ortaya çıkmaktadır. Gölge arketipi, Carl Gustav Jung'un kolektif/ortak bilinç dışı kuramında yer alan önemli arketiplerden birisidir. Gölge; insan, toplum ve medeniyet tarafından hoş karşılanmadığı için bilinç dışına bastırılan ilk benliğimizdir. Gölgenin ortaya çıkmasına imkân sağlayan nedenlerden biri kitledir. Bireyin psikolojisine nazaran kitle psikolojisi birçok durumda farklılık göstermektedir. Bu makale, öncelikle gölge arketipi ve kitle psikolojisini tanımlamaya, daha sonra Yusuf Atılgan'ın, "Çıkılmayan” adlı öyküsünde gölge arketipi ve kitle psikolojisinin başkarakter üzerindeki etkisini anlamlandırmaya çalışacaktır.

Anahtar sözcükler: Yusuf Atılgan, Gölge Arketipi, Kitle Psikolojisi, Arketipsel Eleştiri, Gölge, Kitle, Öykü

\section{THE SHADOW ARCHETYPE AND MASS PSYCHOLOGY IN THE STORY OF “ÇIKILMAYAN” BY YUSUF ATILGAN}

\section{Abstract}

In literary works, the archetypes arise in various forms. The shadow archetype is one of the most important components of Carl Gustav Jung's collective unconscious theory. The shadow is our primary ego suppressed to unconscious since it is not well received by the society and civilization. One of the reasons that urge the shadow to appear is the mass, and mass psychology is more changeable than individual pschology in many cases. This article primarily aims at defining the shadow archetype and mass psychology and secondly, it tries to explain their effect on the protagonist in the story of "Çıkılmayan" by Yusuf Atılgan.

Keywords: Yusuf Atılgan, The Shadow Archetype, Mass Psychology, Archetypical Criticism, Shadow, Mass, Story

\section{Giriş \\ rketiplerin, "bilinçten önce var olan kavrayış biçimleri” ya da "sezginin
doğuştan gelme koşulları" olduğu söylenmektedir. Jung, çalışmalarının
başında J. Burckhardt'dan aldığ “ilk imgeler" terimini kullanmış, daha}

\footnotetext{
* Ege Üniversitesi Sosyal Bilimler Enstitüsü, aturut91@gmail.com
} 
sonra bilinci ve bilinç dışını kapsayacak bir şekilde "arketip" terimini tercih etmiştir (Fordham 2015: 28).

Arketipler bilinç dışının temelini oluşturmaktadır. Carl Gustav Jung, bilinç dişını bireysel ve kolektif olmak üzere ikiye ayırır. Bireysel bilinç dışımız; hoşlanmadığımız, unutmak istediğimiz, rahatsızlık duyduğumuz, bu yüzden de bastırdığımız pek çok şeyin bulunduğu kısımdır. Kişisel deneyimlerimiz bunların kaynağıdır. Kolektif bilinç dışı ise kalıtsal olarak doğuştan bu yana taşıdığımız, ilk insandan günümüze değin beraber olduğumuz yapıdır. Yalnız bir insanı değil, bütün insanlığı kapsamaktadır (Fordham 2015: 25-27). Kolektif

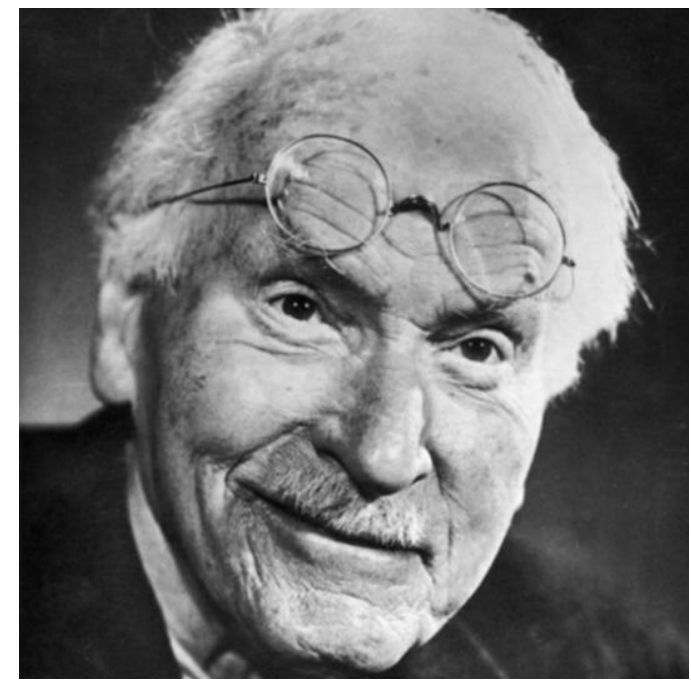

Carl Gustav Jung bilinç dışını; anne, benlik, persona, gölge, anima, animus vb. arketipler oluşturur. Biz bu çalışmamızda, Yusuf Atılgan'ın "Çıkılmayan” adlı öyküsünü, gölge arketipi ve kitle psikolojisi bağlamında ele alacağız.

\section{Gölge Arketipi}

Jung'a göre bireysel bilinç dışımız iki yüzden oluşmaktadır: Persona ve gölge. Persona, insan doğasının toplum ve uygarlık tarafından belirli bir kalıba sokulmuş hâlini ifade eder. O, dünya ile ilişkilerimizi sağlamaya yarayan bir gerekliliktir (Fordham 2015: 63). Persona ile birlikte bireysel bilinç dışımızı oluşturan gölge, maskelerin ardındaki ilk benliğimizdir; madalyonun öbür yüzüdür. İlk çağlardan bu yana var olagelen, ilkel ve hayvanî isteklerimizin kaynağını gölge oluşturmaktadır. İnsanlığın uygarlaşma süreciyle birlikte değişmeyen, daima aynı kalan ve bilindik yollarla eğitilemeyen yanı olmakla birlikte gölge; doğal ve irsîdir (Fordham 2015: 65). Gölgenin birtakım yollarla anlaşılmaz ve yok edilemez oluşu, onun bilinç dışına itilmesine neden olmuştur (Jung 2005: 130).

Bireysel bilinç dışına itilen gölge, orada varlığını sürdürmeye devam eder. Her ne kadar gölge figürü bilinç dışı olarak kabul edilse de bilinçten beslenmektedir. Jung'un deyimiyle, güneş olmadan gölge olmaz (Fordham 2015: 65). Dolayısıyla gölge kaçınılmaz bir olgudur. Onu yadsımak ya da bastırmaya çalışmak boşunadır. Birey için zihinsel ve bedensel sağlığı korumanın yolu bilinç ve bilinç dışını dengede tutmaktan geçer. Bu yüzden gölgenin varlığını kabul etmek ve onunla birlikte yaşamanın yollarını bulmak gereklidir. Gölgeyle yüzleşmek, birey ve toplum açısından değer verilen ahlakî kuralların, ideallerin ilkel benliğin bencil istekleriyle çatışmasına yol açar; ancak gölge figürünü bilinçte tutmanın ve 
bilinçli bir eleştiri yönelterek onu kontrol altına almanın en başarılı yolu bu çatışmayı tecrübe etmekten geçer (Jung 2005: 130).

Gölge figürü, kişisel hatalarımız, zayıflıklarımız söz konusu olduğu sürece kişiseldir; ancak gölge, bütün bireylerde ayrı ayrı bulunduğu için kolektif bir yönü de vardır. Gölgenin kolektif yönü, toplumun bünyesinde barındırmak istemediği cadı, şeytan gibi şekillerde vücut bulur. Bireyin bilinç dışına nazaran toplumunki daha tehlikeli olmaktadır. Toplumu baskı altında tutan unsurlar gölgenin bilinç dışında gittikçe büyümesine ve şiddetin artmasına neden olur. Kitle isyanlarında, yağma ve linç girişimlerinde, zararsız görünen insanların; kolektif bilinç dışı ve kitlenin etkisiyle vahşi ve yıkıcı davranışlar sergiledikleri görülmektedir (Fordham 2015: 67).

\section{2. “Çıkılmayan” Öyküsünde Kitle Psikolojisi ve Gölge Arketipi}

“Çıkılmayan” öyküsü, bir yağma sahnesiyle başlar. Öykünün isimsiz karakteri kendi hâlinde işinden evine dönen bir memurdur. Sokakta, dükkânları yağmalamaya başlayan kalabalığın peşine takılır. Yağmalanan dükkânların birinde bulduğu para tomarını kimseye görünmeden cebine atar. Kalabalık dağıldıktan sonra etrafını kollayarak evine

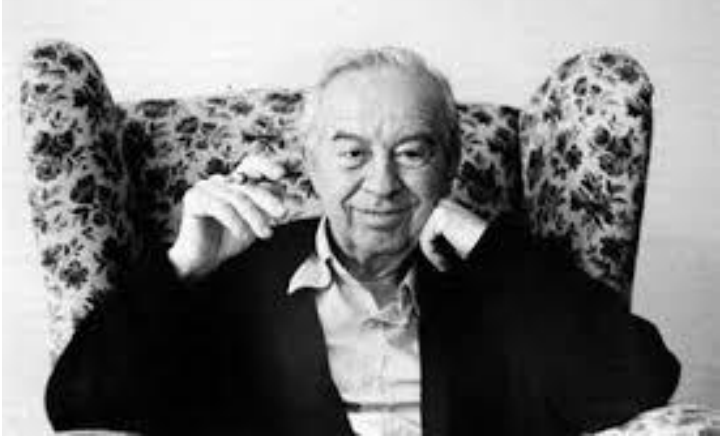

Yusuf Atılgan dönmeye çalışır. Bu süre zarfında isimsiz karakter, diğer insanlar ve polisler tarafından sürekli izlendiği ve paraları çaldığının bilindiği zannıyla tedirgin olmaktadır. Her zamanki güzergâhını kullanmak yerine yan sokaklardan dolaşarak evine varır. Dükkândan çaldığı paraları yatağının içine saklar. Bütün gece dişinin ağrısı ve gördügü kâbus yüzünden sabahı zor eder. Ertesi gün dairede gece yaşanan olaylar konuşulmaktadır. Bunun üzerine, dairedeki arkadaşlarının kendisini görmüş olabileceklerinden kuşkulanır. Bütün bir mesaiyi bu endişe ve diş ağrısıyla geçirir. Kendi kendine sürekli yakalanacağı telâşıla yaşar; sokaktaki insanlardan, arkadaşlarından kaçmaya çalışır. O günün akşamı eve gider gitmez sakladığı paraları kontrol eder. Paralara kimse dokunmamıştır; ancak kendisini bir türlü kuşkuya kapılmaktan alıkoyamaz. Bu süreçte çürük dişi dayanılmaz bir şekilde ağrımaya devam eder. Daha sonra paraları aldığı dükkâna geri götürmek ister; fakat, dükkân sahibinin ona inanmayacağına hükmeder. Sonunda paraları yakarak kurtulmayı düşünür. Tomarın içinden aldığı iki yüz lira dışında kalan paraları mangalda yakarak onlardan kurtulur. Bundan böyle yapacağı ilk iş olarak çürük dişini çektirmeyi kafasına koyar (Atılgan, 2013: 64-69). 
Öyküde işaret edilmeyen bir nedenden ötürü galeyana gelmiş bir kitle, dükkânları yağmalamaktadır. Herhangi bir adı olmayan öykünün başkarakteri, bu kitleye sonradan dâhil olur. Bu noktada başkarakterin içinde bulunduğu ruh hâlini anlamak için öncelikle kitleyi tanımak gereklidir; çünkü kitle, kalabalığı oluşturan bireylerden birçok alanda farklılık göstermektedir.

"Kitleyi meydana getiren bireyler kimler olursa olsun; onların yaşama biçimleri, işgüçleri, karakterleri yahut zekâları ister benzer, ister ayrı olsun, kalabalık haline gelmiş olmaları onlara bir nevi kolektif ruh aşılar. Aşılanan bu ruh onları, her biri tek başına, ayrı ayrı bulundukları halde duyacaklarından, düşüneceklerinden ve yapacaklarından tamamıla başka hissettirir, düşündürür ve yaptırır. Bazı düşünceler, bazı duygular ancak kitle halinde bulunan bireylerde kendini gösterir veya hareket alanına çıkar." ( Le Bon, 2015: 24)

Kitleler içinde yer alan bireyin başlıca özellikleri nelerdir? Kitlenin kolektif gücünün etkisinde bulunan birey, tek başına olduğundan daha farklı hareket etmektedir. Öncelikle bilinçli kişilik, düşünme mefhumu silinir ve bilinçten bilinçaltı/bilinç dışına doğru bir yöneliş meydana gelir. Birey, kitlenin telkin ettiği düşünceleri, bir an önce hayata geçirme isteğine kapılır; fevri ve düşünmeden hareket eder. Bu özellikleri taşıyan insanın iradesi kendi elinden çıkmış, kitlenin kontrolüne geçmiştir. Bundan böyle bireyin arzusundan çok, kitlenin arzusu söz konusudur (Le Bon, 2015: 27-28).

Kitle, bilinç dışı bir olgudur. Bilinçli düşünemeyen ve kitlenin bir parçası hâline gelen birey, farkında olmadan gölgenin ortaya çıkmasına müsait bir ortam hazırlamıştır. İlkel kişiliğimizin bir yanını oluşturan gölge, kitleleri oluşturan bireylerde ilkel, ırsî içgüdülerin gün yüzüne çıkmasına neden olur. Birey tek başınayken bilinçli bir müdahaleyle bu içgüdüleri bastırmaya uğraşır; ancak kitle hâlinde olduğunda bu mekanizmayı gerektiği gibi kullanamaz. Çünkü kitleye bilinç ve mantıktan çok bilinçaltı, aşırı duygular ve heyecan hâkimdir.

"Yıkıcı gaddarlık içgüdüleri, her birimizin ruhunda uyuyan, ilkel devirlerin sonuçlarıdır. Tek başına birey için bu içgüdüleri tatmin etmek tehlikeli olur, hâlbuki bireyin sorumsuz ve cezasız kalacağından emin bulunduğu kitleye karışması, kendisine bu içgüdülere uymak için bütün serbestlikleri verir." (Le Bon 2015: 53)

“Çıkılmayan" öyküsünün isimsiz karakteri, piyangodan zengin olmak, onu özgürlüğe kavuşturacak bir otomobile sahip olmak gibi hayaller kuran, her gün karşılaşabileceğimiz orta sınıf bir memurdur (Gülsoy, 2012). Onu para tomarını almaya iten nedenler, içinde bulunduğu kitlenin aşırılığı ve kendi gölgesinin ilkel istekleridir. Eğer parayı alırsa, kendi ifadesiyle; sevmediği, alışamadığı işinden kurtulacak ve bu para sayesinde özgür kalabilecektir (Atılgan 2013: 65). Tamamen özgür olmak, dilediğince hareket etmek gibi 


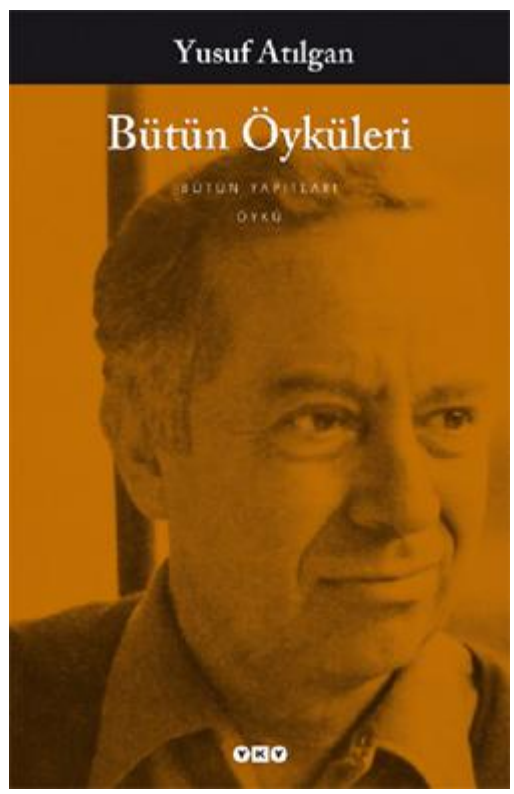

arzular bencil ve vahşi olan gölgeye aittir. Diğer yandan bir başkasına ait olan parayı çalmak, toplum kurallarına ve yasalara göre suçtur. Dolayısıyla paraları çaldığı takdirde yasal olarak suçlu, vicdanen de paralarını çaldığı insanlara karşı sorumlu duruma düşecektir; ancak paraları cebine attığ1 sırada bunların hiçbirini düşünmez. Tek derdi yakıp yıkmak olan kalabalığın içinde, kendi iradesine hâkim olamaz (Oğuz 2012: 1661). İşte burada, iradesindeki zayıflık gölgenin harekete geçmesini ve paraları düşünmeden cebine atmasını sağlamıştır. Bundan böyle isimsiz karakter, kitlenin coşku dairesinden dışarı çıkmaya başladığı sırada, kendi iradesi ve bilinciyle karşılaşır. "Şimdi yalnız. Para tomarını avuçlayalı beyninin saati kuruldu. Dışarının uğultusunu duyuyor. Anlamsız bağrışların karması bir uğultu bu. Korkutuyor onu." (Atılgan 2013: 65)

"Beyninin saati kuruldu" ifadesi, daha önce yapıp ettiklerinin bilincinde olmadığını işaret etmektedir. $\mathrm{O}$ süre zarfında gerçekleştirdiği edimleri gölgenin etkisiyle yapmıştır; ancak yalnız kaldığı zaman, kitlenin ezici etkisinden soyutlandığında bilinçli bir şekilde düşünebilmektedir. Bireyin pişmanlık bildiren ve farkında olmadan yaptıkları hakkında, "kendimde değildim", "gerçekten bana ne oldu bilmiyorum", “Ben mi yaptım?" gibi söylemleri, gölgenin kendisini işaret etmektedir. Gerçekte bu zamanlarda, bireye ait olan gölgenin; ilkel, denetimsiz ve hayvanî yanının ortaya çıkmasıdır (Fordham 2015: 64). “Caddenin 1şıklarıyla azalan karanlığına alışınca paçavra yığınları üstünde kırık oyuncaklar gördü. "Bebekler başlarına gelenden şaşkındırlar. Ben mi kırdım onları?" Hatırlayamadı." (Atilgan 2013: 65).

Öykünün isimsiz karakteri, paraları çaldığı andan, yok etmesine kadar geçen süre zarfında gölge figürü, değişik şekillerde karşımıza çıkmaktadır. Bunlardan biri daima takip ediliyor hissi ve yaptığı yanlışın başkaları tarafından biliniyor olduğunu düşünmesidir. İsimsiz karakter, herkesten ve her şeyden kuşku duyar. Sokakta, işinde ve evinde sürekli takip edildiğini düşünmekten kendini alıkoyamaz. Caddeden gelip geçenler, iş arkadaşları, onun gözünde parayı çaldığını bilmekte ve kendisini yakalamak için fırsat kollamaktadır.

"Sağdaki sokağa saptı. Ağzından soluyordu, sık sık, “íki kişi var ardımda. İzliyorlar beni." Sağa saptı. Daha hızlı koşmak istiyordu. Bir ekse şu ardından koşanları. [...] "Yüreğim bu kadar hızlı çarpsın da durmasın. Koşamam artık. Yakalayacaklar beni." Dönüp baktı; kimse yoktu ardında." [...] "Sabahki şemsiyeli adamı hatırladı. Hangi sokağa gitse ardından geliyordu." (Atılgan 2013: 66) “İzleniyordu. Omuzları kasıldı. “Vay canına, sabahki adam bu. Şemsiyesini 
bırakmış ama o." Önüne çıkan ilk sokağa saptı. Hızlandı. Kurtulamıyordu ayak seslerinden."(Atılgan 2013: 68)

Gerçekte bütün bu ruh hâli, kendi vehminden başka bir şey değildir; ancak paraları çalmasından ötürü duyduğu vicdan azabı onu rahat bırakmamıştır. Bir kere hakkı olmamasına rağmen kendisine ait olmayan parayı almış, gölgesinin isteklerine boyun eğmiştir. Bundan böyle sevmediği işine gitmeyecek, hayalini kurduğu otomobili alabilecektir. Gölgenin arzuladığı da budur. Her ne kadar gölgesini dinlese de, iradesi bir taraftan onu sürüncemede bırakır. Bu noktada gölgesi ile iradesi arasında çatışma ortaya çıkar. İsimsiz karakterin, “Canımın çektiği gibi yaşasam şu dünyada.”(Atılgan 2013: 67) gibi sitemvari sözleri, kendi iradesinden çok gölgesinin etkisiyle sarf edilmiş sözlerdir. Gölge, içinde yaşadığı toplumun bastırdığı arzuları fırsatını bulduğunda gün yüzüne çıkarmaya çalışmaktadır.

Diğer yandan gölge figürü, isimsiz karakterin diş ağrısında karşımıza çıkmaktadır. Diş ağrısı, tıpkı gölgesi gibi onu daima zayıf düşüren ve bilinçli karar vermesini engelleyen bir etkiye sahiptir. Dükkândaki paraları alır almaz, dişçi çekiciyle vurmuş gibi çürük azı dişinin acısını duyar (Atılgan 2013: 64). Bundan böyle diş ağrısını daima hissedecektir. F. Fordham, gölgenin, aşağılık ya da hoşlanmadığımız biri olarak rüyada karşımıza çıktığını söylemektedir. (2015: 65) Bu bağlamda isimsiz karakter, paraları çaldığı gece rüyasında, dişçiler tarafından kuşatıldığı sancılı bir kâbus görür. "Az sonra uyudu. Bütün gece yitirip yitirip buldu parasını. Çevresini dişçiler kuşattı. Çürük dişine çekiçle tak tak vurdular." (Atılgan 2013: 66) Bu rüyalar ve ağrı nöbetleri, isimsiz karakterin gölgesi karşısında yenik düştüğünü göstermektedir. Paraları çalmış, harcamayı düşünmüş, daha sonra saklamıştır; gölgenin istediği doğrultuda hareket etmiştir.

Bu bakımdan isimsiz karakter, gölgesiyle çetin bir yüzleşme içerisindedir. Gölgenin arzu nesnesi, yağmalanan dükkândan alıp gizlice evine götürdüğü paralardır. Jung'un işaret ettiği gibi gölgeden tamamen kurtulmak imkânsızdır, gölge yok edilememektedir. Onu bastırmak ve yadsımak da en az yok etmeye çalışmak kadar tehlikelidir. Kişi onun varlığını kabul etmeli ve onunla yaşamanın bir yolunu bulmalıdır (2005: 130). O, yüzleşme sonrasında gölgeyi kabul etmiş ve ondan kurtulamayacağını kavramıştır. “Belli bir yaşayış uygulamışlar bana. Görünmeyen bir giysi giydirmişler. Sıkıyor beni, çıkarıp atamıyorum. Düğmelerini çözemem mi? Bu bile güç." (Atılgan 2013: 68)

\section{Sonuç}

Edebî eserlerde arketipler çok farklı şekillerde ortaya çıkmaktadır. "Çıkılmayan" öyküsünde başkarakterin çaldığı para tomarından başlayıp, onları yakıp kurtulmasına kadar geçen süre boyunca, gölge arketipinin girdiği şekilleri ve karakter üzerindeki etkisini 
gözlemlemek mümkündür. Kitlenin aşırılığı ve birey üzerindeki kontrol edici gücü, karakterin gölgesinin gün yüzüne çıkmasına imkân sağlamıştır. Kitlenin yanında bir birey olarak bireysel bilinç dışı, yani gölgesinin arzuları da etkili olmuştur; ancak, toplumun koyduğu kuralları çiğnemesi, onu içten içe rahatsız etmektedir. İsimsiz karakter, yaptığının yanlış olduğunu bilir ama diğer yandan özgür olmak, bir otomobile sahip olmak için bu paraya ihtiyacı vardır. Benliği ve gölgesi ile girdiği çatışma boyunca tedirgin ve kuşkuludur. Gölgenin diş ağrısı ile ortaya çıkması ve dişçi, hayali takipçi, polis gibi şekillerde görünmesi, onu bir an dahi yalnız bırakmaması, iradesini zayıflatmıştır. Ne yaparsa yapsın gölgeden kurtulamayacağını anlamış; nihayetinde yok edilemeyen gölgenin yerine, onun arzu nesnesi olan paralardan kurtulmayı seçmiştir. Arzu nesnesinin ortadan kalkmasından sonra iradesi tekrardan hâkimiyeti eline almış, benliğinin bir parçası ve karanlık yönü olan gölgeyle yaşamanın kendine göre çaresini bulmuştur.

\section{Kaynakça}

Atılgan, Yusuf (2013). Bütün Öyküleri. İstanbul: Yapı Kredi Yayınları.

Fordham, Frieda (2015). Jung Psikolojisinin Ana Hatları. Çev. Aslan Yalçıner. İstanbul: Say Yayınları.

Gülsoy, Murat (2012). "Küçük Yağmacının Otomobil Sevgisi". https://muratgulsoy.wordpress.com/2012/09/30/kucuk-yagmacinin-otomobil-sevdasi/ Erişim Tarihi: 10 Ekim 2016.

Jung, Carl Gustav (2005). Dört Arketip. Çev. Zehra Aksu Yılmazer. İstanbul: Metis Yayınları.

Le Bon, Gustave (2015). Kitleler Psikolojisi. Çev. Fatma Zehra Bayrak. İstanbul: Hayat Yayınları.

Oğuz, Orhan (2012). "Yusuf Atılgan'ın Hikâyelerinde Kent". Turkish Studies, International Periodical For The Languages, Literature and History of Turkish or Turkic Volume 7/1 Winter 2012, s. 1653-1669. 